\title{
Evaluation of Big Data Analytics in Medical Science
}

\author{
Iwan Kurniawan Subagja, Nurhadifah Amaliyah, Ulpen Hiermy, Budi Tri Rahardjo, E. Laxmi \\ Lydia, K. Shankar, Phong Thanh Nguyen
}

\begin{abstract}
In medical science the concept of big data is very important because in the diseases prevention outcome prediction of co-morbidities, mortality and it save the cost of medical treatment it can used. In the evolution of healthcare research and practices the continuously growing field of analytics of big data has play a pivotal role. To analyze, accumulate, assimilate and manage huge volume of structured, disparate and unstructured data that produced by recent system of healthcare, it provide the tools. To inform providers about most effective and efficient treatment pathways and to revamp the health care delivery process the big data of healthcare has the potential. Both insurers and health care providers are incenting by Value-based purchasing programs. To estimate the efficiency and quality of care to find the new ways to leverage health care data defined the insures. During routine health care in data collection current advances in the form of EHR (Electronic Health Records), for clinical application in biological discoveries medical device data have created major opportunities.
\end{abstract}

Keywords : Big data, healthcare, clinical application, medical treatment.

\section{INTRODUCTION}

It can referred that big data is a field that that treats approaches to investigate, methodically separate data from, or generally manage informational indexes that are too huge or complex to be managed by customary information preparing application programming. For certain advanced data analytics methods, predictive analytics and user behavior analytics the term big data used. These methods from data extract the value and sometimes to a specific size of data set [1].

The big data concept is not new although anyway the manner in which it is characterized is always showing signs of change. Different endeavors at characterizing big data basically portray it as an accumulation of information components whose type, speed, size and complexity need one to adopt, invent and seek new software mechanisms and

Revised Manuscript Received on September 22, 2019

* Correspondence Author

Iwan Kurniawan Subagja, Universitas Krisnadwipayana Jakarta, Indonesia.

Nurhadifah Amaliyah, Universitas Megarezky, Indonesia.

Ulpen Hiermy, Sekolah Tinggi Teknologi Bina Tunggal Bekasi, Indonesia.

Budi Tri Rahardjo, Universitas Krisnadwipayana Jakarta, Indonesia.

E. Laxmi Lydia, Professor, Vignan's Institute of Information Technology(A), Department of Computer Science and Engineering, Visakhapatnam, Andhra Pradesh, India.

K. Shankar, Department of Computer Applications, Alagappa University, Karaikudi, India.

Phong Thanh Nguyen*, Department of Project Management, Ho Chi Minh City Open University, Vietnam. E-mail: phong.nt@ou.edu.vn hardware so as to effectively visualize, store and analyze the data [2-4].

From volume-based business to value-based business the current healthcare industries are moving. To be more efficient and productive from nurses and doctors it requires an overwork. In many nations several healthcare information systems are proposed to obtain the best care and services for the patients. On using of large amounts and electronic health records (EHRs) of complex biomedical data these models for preventive medicine, personalized, predictive and participatory medicine are based [5].

For big data in industry of healthcare several sources incorporate medical examinations results, hospital records, devices and patients medical records that are a piece of internet of things. Relevant to public healthcare the biomedical research additionally produces a significant segment of big data. In order to determine significant data this data needs proper analysis and management [6]

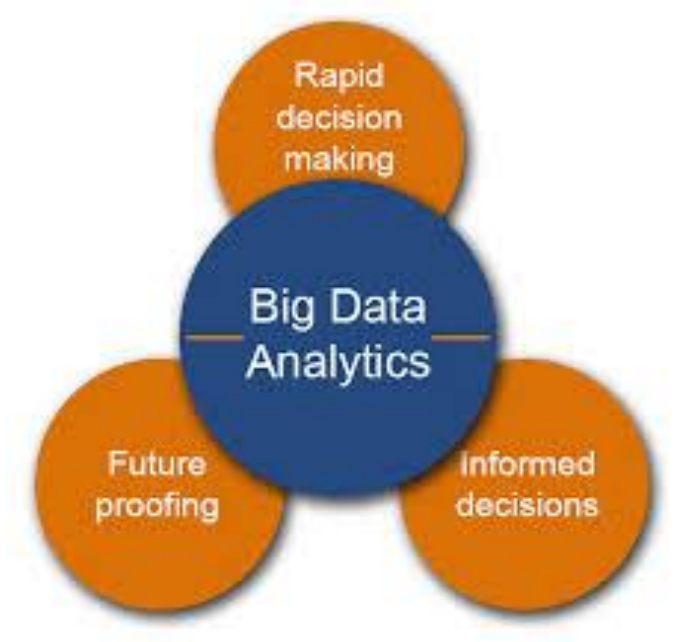

Figure 1: Big Data Analytics

\section{BIG DATA ANALYTICS IN MEDICAL SCIENCE}

To information revolution and embrace digitization many organizations deliberate and conscious deliberate. However the job of big data in medication appears to be nearly to urge associations to wind up included.

For better treat disease and diagnose in medical the role of big data is one where it can construct better predictive models and health profiles around individual patients. In the pharmaceutical industry and medicine the main limitations is the comprehension of the science of disease. Big data becomes an integral factor

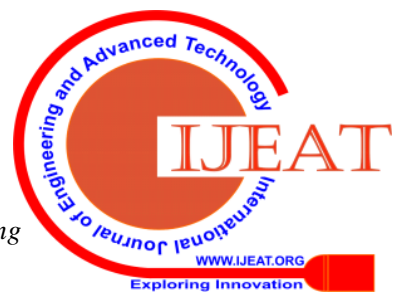


around totaling increasingly more data around numerous scales for what establishes an ailment - from proteins, DNA and organisms, tissues, ecosystems, organs and metabolites to cells. By integrating big data these are the parameters of science that required for modeling. [7].

On medical database the most significant impact are as follows:

1. In potential health problems detection even when there are no apparent symptoms it can do a wonderful job by wearable devices.

2. It take a 360 degree view of health problem of patient in the institute of healthcare that helped by big data.

3. How it delivered the healthcare refined by big data.

4. When on the existing data the medical institutions apply big data then they can find useful, potential and new life saving Knowledge that data are in their database otherwise remained inert.

5. To find more about patients the big data helps. It can find like organisms, lifestyle, family DNA, ecosystems, tissues, metabolites to cells, genetic structure, dietary habits, proteins and organs.

6. The additional patterns, visualizing record, data related to sensor, EHR (electronic health record) data and patient arrangement data included in big data towards data progress.

7. To reduce costs of predict outbreaks of epidemics, treatment, to improve the quality of life in general and avoid preventable diseases it have the potential by medical analytics.

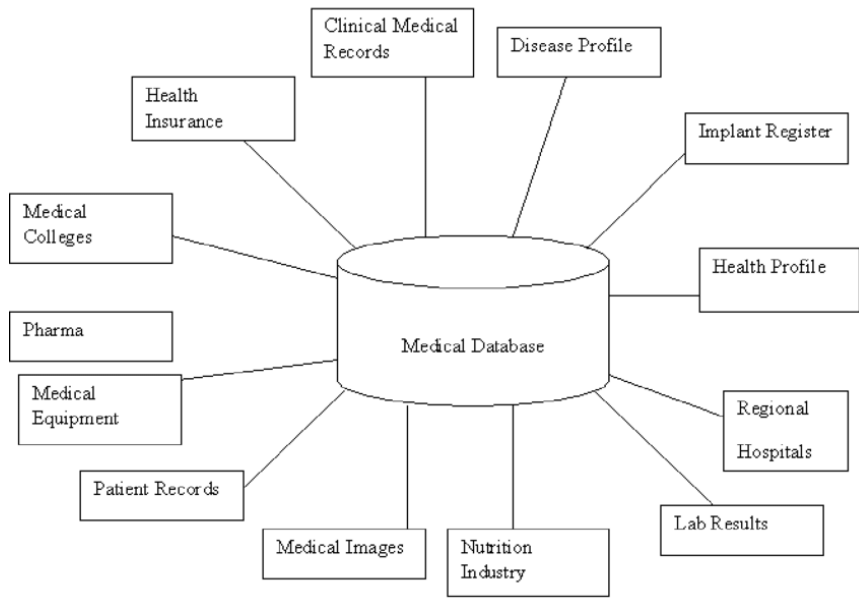

Figure 2: medical database

\section{SOURCES OF MEDICALDATA}

There are several sources of medical data are available. Some of them are described as follows:

1. To accumulate at a rapid pace the human genetic information repository continues. At Harvard Medical School in 2005 PGP (Personal Genome Project) launched, from around the world to publicize and sequence seeks the complete genomes of 100,000 volunteers. Due to variety of data and sheer volume the PGP is consider as prime example of big data project.

2. EMR (Electronic medical records) are differ from HER and generally with a specific physician pertain to data stored.

3. Some record of events like birth, immigration, death and marriage are kept by governments.

4. EHR (Electronic health records) display, store and collect the information like vital signs, immunizations, results from the test of radiology or laboratory, past medical history, pathology reports, allergies, active medical problems, medications are consider as big data sources.

5. About clinical outcomes, study participants and experimental treatments the information are contain by research databases.

6. Between system of disparate clinical information Patient registries it exchange the health information, on their patients the health care organizations maintained it [8].

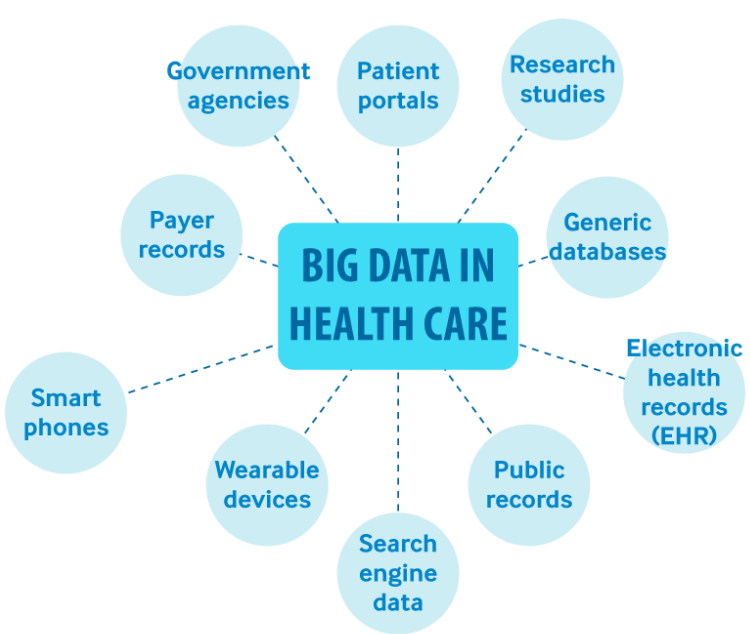

Figure 3: Sources of Big Data

\section{APPLICATIONS FOR BIG DATA IN HEALTHCARE}

At the front of any priority list to avoiding disease and illness and to keep the patient healthy it stands.

On the physical activity levels of any person Apple Watch keep tabs and like Fitbit activity tracker's consumer products can report on particular trends related to health. The information that are required by a physicians sent to the cloud servers that use these information as a part of complete wellness and health program [9].

From volume-based business to value-based business the current healthcare industries are moving. To be more efficient and productive from nurses and doctors it requires an overwork. In many nations several healthcare information systems are proposed to obtain the best care and services for the patients. 


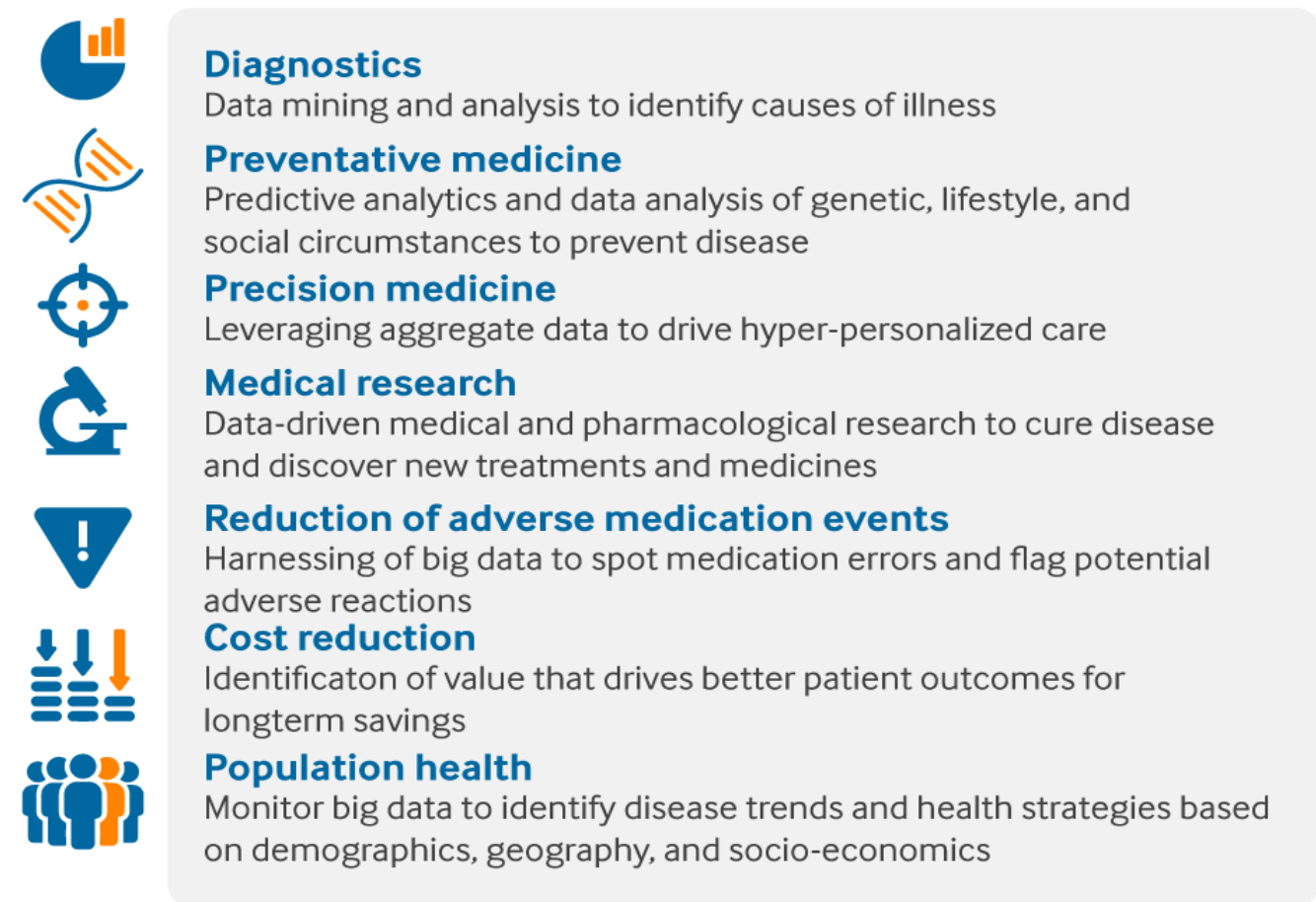

Figure 4: Applications for big data in healthcare

\section{IN MEDICAL SCIENCE CHALLENGES OF BIG DATA}

In medical science the use of big data face some challenges. They are as follows:

1. In the right context unstructured clinical notes understanding.

2. Through several sensors capture the behavioral data of patient, their several communications and social interactions.

3. Huge amount of medical imaging data handle efficiently and extract potentially useful biomarkers and information.

4. From complex heterogeneous sources of patient inferring knowledge [10].

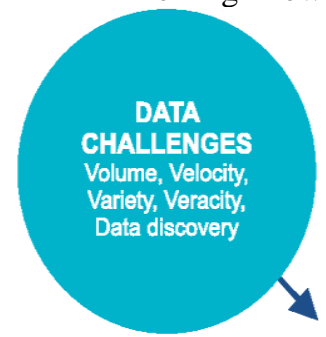

\section{BIG DATA}
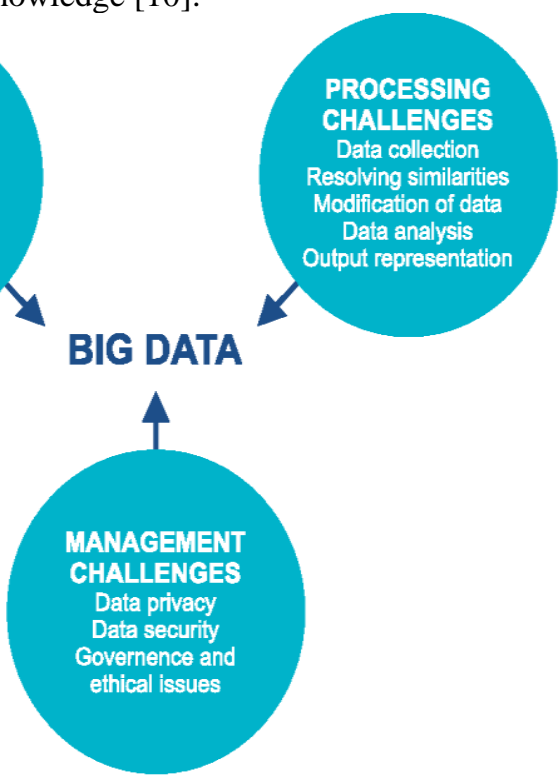

Figure 5: Big Data Challenges

\section{EVALUATION OF BIG DATA}

In last two years it come the popularity of big data. In all the fields actually big data is enhancing exponentially.

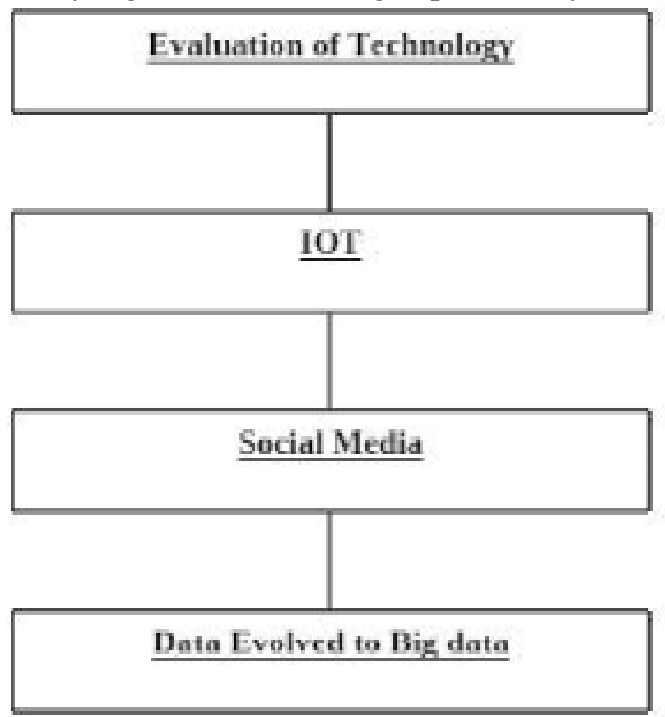

Figure 6: Evolution of Big data

\section{HEALTHCARE DATA ANALYTICS AND TOOLS AND PLATFORMS}

1. AVRO: It encourages information encoding and serialization, which improves information structure by determining information types, which means and plan [11].

2. OLTP (Online Transaction Processing): It is like OLAP, however it is assigned to process patient consideration activities, for example, tolerant enrollment, emergency clinic reports and results audit [12].

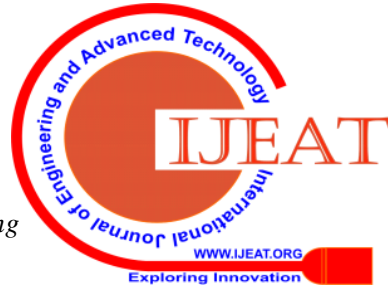


3. Text Mining: Text Mining instruments can be utilized and include an incentive in social insurance as far as investigating clinical records from the medical clinic crisis branches of doctor reaction accessible if the need arises, as a comparable objections called the crisis office and were dealt with distinctively relying upon the individual who picked up the telephone. Such issue can impact in the nature of medicinal services, just as expenses. In this way, content mining can offer a treatment plan which will build up certain principles and conventions to comprehend this issue

4. Mahout: It is an apache undertaking intends to produce applications that support human services information examination on Hadoop frameworks [13].

5. ADV (Advanced Data Visualization): It is not quite the same as different norms bars and line outline, since it can scale its representation for many information focuses, likewise can deal with various information types. ADV is anything but difficult to utilize and bolsters examiners to investigate information generally [14].

6. CFS (Casandra File System): It is additionally appropriated framework like HDFS, anyway CFS is an assigned framework to perform diagnostic activity with no single purpose of disappointment [15].

\section{CONCLUSION}

In medical science the concept of big data is very important because in the diseases prevention outcome prediction of co-morbidities, mortality and it save the cost of medical treatment it can use. It can referred that big data is a field that that treats approaches to investigate, methodically separate data from, or generally manage informational indexes that are too huge or complex to be managed by customary information preparing application programming. For big data in industry of healthcare several sources incorporate medical examinations results, hospital records, devices and patients medical records that are a piece of internet of things. For better treat disease and diagnose in medical the role of big data is one where it can construct better predictive models and health profiles around individual patients.

\section{REFERENCES}

1. Simpao A.F., Ahumada L.M., Gálvez J.A., Rehman M.A. A review of analytics and clinical informatics in health care. J. Med. Syst. 2014;38:45. doi: 10.1007/s10916-014-0045-x.

2. A. McAfee, E. Brynjolfsson, T. H. Davenport, D. J. Patil, \& D. Barton (2015), "Big data: the management revolution," Harvard Business Review, vol. 90, no. 10, pp. 60-68.

3. C. Lynch (2008), "Big data: how do your data grow?" Nature, vol. 455, no. 7209 , pp. $28-29$.

4. A. Jacobs (2009), "The pathologies of big data," Communications of the ACM, vol. 52, no. 8, pp. 36-44,

5. Yang C, Li C, Wang Q, Chung D \& Zhao H(2015). "Implications of pleiotropy: challenges and opportunities for mining big data in biomedicine". Front Genet. 2015, vol.6, issue.229.

6. Moher D., Liberati A., Tetzlaff J., Altman D.G., Group P. Preferred reporting items for systematic reviews and meta-analyses: The PRISMA statement.

7. Tomar D., Agarwal S. A survey on Data Mining approaches for Healthcare. Int. J. Bio-Sci. Bio-Technol. 2013.

8. Bellazzi R., Ferrazzi F., Sacchi L. Predictive data mining in clinical medicine: A focus on selected methods and applications. WIRE. 2011;1:416-430. doi: 10.1002/widm.23.

9. Sigurdardottir A.K., Jonsdottir H., Benediktsson R. Outcomes of educational interventions in type 2 diabetes: WEKA data-mining analysis. Patient Educ. Couns. 2007;67:21-31.
10. Jimeng Sun \& Chandan K. Reddy, "Big Data Analytics for Healthcare". https://archive.siam.org/meetings/sdm13/sun.pdf

11. Powell, James E. (2014), "Q\&A: Advanced data visualization: from atomic data to big data."

12. Ledbetter, Craig S. \& Morgan, Matthew W.(2001), "Toward best practice: leveraging the electronic patient record as a clinical data warehouse". Journal of Healthcare Information Management, vol.15, issue.2, pp.119-131.

13. Lakshman, A. \& Malik, P.(2010), "Cassandra: a decentralized structured storage system”, Operating Systems Review, vol.44, issue.2, pp.35-40.

14. Raja, U., Mitchell, T., Day, T. \& Michael Hardin, J. (2014). “Text mining in healthcare. Applications and opportunities".

15. Raghupathi W., Raghupathi V. Big data analytics in healthcare: Promise and potential. Health Inf. Sci. Syst. 2014;2:3. 